\section{VASOCONSTRICTIVE AND APOPTOGENIC MECHANISMS OF CHRONIC KIDNEY DISEASE DEVELOPMENT AND PROGRESSION IN CHILDREN}

\author{
G. Senatorova, N. Makieieva, I. Pasichnik
}

\section{Pediatrics and Neonatology, Kharkiv National Medical University, Kharkiv, Ukraine}

Background: Calpains and nonthrypsinlike proteinase are known to participate in apoptogenic and vasoconstrictive reactions in various types of chronic disease, but their role in chronic kidney disease (CKD) at children is poorly understood. Hence, we questioned whether calpains, chymase and tonin could play a role in the pathogenesis of CKD development and progress in children.

Methods: We investigated calpains and nonthrypsinlike proteinase activities in blood serum and urine, using high sensitive $\left(10^{-9}-10^{-10}\right)$ enzyme techniques, in 58 ( 37 male, 21 female, mean age $13,79 \pm 2,71$ years) patients with stage I-V nondiabetic CKD (group I $(n=16)$ with stage I ; group II ( $n=19)$ - with stage II; group III $(n=12)$ with stage III; group IV ( $n=11)$ with stages IV-V) and 12 healthy children ( 7 male, 5 female; mean age $13,1 \pm 0,7$ years) - group VI (controls).

Results: Comparison of CKD patients and controls showed the gradual increase of apoptogenic and vasoconstrictive mechanisms activation in progress to chronic renal failure. The high level of distinctions between groups by calpains and nonthrypsinlike proteinase activities in blood serum and urine was determined.

Conclusions: These results demonstrated correlative nature of nonthrypsinlike proteinase and calpains activities in blood serum and urine. It is possible to use for prognosis of vasoconstriction and apoptogenic changes development at chronic kidney disease in children.

\section{COMPARISON OF DMSA RENAL SCINTIGRAPHY AND MICTURATING CYSTOURETROGRAPHY IN CHILDREN WITH URINARY TRACT INFECTION}

\section{B. Ajdinovic ${ }^{1}$, L. Jaukovic ${ }^{1}$, Z. Krstic ${ }^{2}$, M. Dopudja \\ ${ }^{1}$ Military Medical Academy, ${ }^{2}$ University Pediatric Clinic, Belgrade, Serbia}

Background and aim: The relationship among urinary tract infection (UTI), vesicoureteral reflux (VUR) and permanent renal damage in children is not fully understood. We aimed to determine the change in probability of permanent renal damage due to the presence of VUR .

Patients and methods: 201 children with UTI, referred for dimercatpo-succinic renal scintigraphy (DMSA) 4-6 months after acute UTI. Micturating cystoureterography (MCU) was one month prior to DMSA. Likelihood ratio (LR) positive and negative, diagnostic odds ratio (DOR) and post test probability of (no) disease were calculated for VUR on MCU versus scarring on DMSA.

Results: VUR was found in 118 patients. Of the 201 patients 55 (27.4\%) had permanent renal damage according to DMSA. Scarring was shown in 34.7\% of patients with UTI and VUR and in $16.9 \%$ patients with UTI without VUR ( $p=0.005)$. LR positive was $1.274(95 \% \mathrm{Cl} ; 1.082,1.500)$, LR negative $(0.49$, $95 \% \mathrm{Cl}: 0.28,0.83)$ and DOR was $2.624(95 \%$ $\mathrm{Cl}$; 1.319, 5.223). Rate of scarring significantly increased with VUR of grade III, IV and V. There was no significant difference in the incidence of scarring in children with UTI without VUR and children with low grade VUR $(p=0.292)$. Presence of VUR on $M C U$ increased the chance of renal damage on DMSA by about $13 \%$, whereas the negative MCU increased the chance of no renal involvement by $8 \%$.

Conclusion: MCUG should not be used as a first line test to rule out the permanent renal damage due to UTI. 